This is an electronic reprint of the original article. This reprint may differ from the original in pagination and typographic detail.

Author(s): Karjaluoto, Heikki; Töllinen, Aarne; Pirttiniemi, Janne; Jayawardhena, Chanaka

Title: Intention to use mobile customer relationship management systems

Year: $\quad 2014$

Version:

Please cite the original version:

Karjaluoto, H., Töllinen, A., Pirttiniemi, J., \& Jayawardhena, C. (2014). Intention to use mobile customer relationship management systems. Industrial management and data systems, 114(6), 966-978. https://doi.org/10.1108/IMDS-11-2013-0480

All material supplied via JYX is protected by copyright and other intellectual property rights, and duplication or sale of all or part of any of the repository collections is not permitted, except that material may be duplicated by you for your research use or educational purposes in electronic or print form. You must obtain permission for any other use. Electronic or print copies may not be offered, whether for sale or otherwise to anyone who is not an authorised user. 


\section{INTENTION TO USE MOBILE CUSTOMER RELATIONSHIP MANAGEMENT}

\section{SYSTEMS}

\section{ABSTRACT}

Purpose - The study investigates the behavioral intentions of business-to-business (B2B) sales managers to use mobile customer relationship management (CRM) systems in the course of their day-to-day activities.

Design/methodology/approach - An extended Technology Acceptance Model (TAM) of mobile CRM system adoption is developed and tested with data from 105 international sales managers representing five B2B companies.

Findings (mandatory) - The study extends the TAM framework with three additional constructs derived from mobile technology and sales force automation (SFA) literature, namely personal innovativeness in the domain of IT, perceived risk and perceived reachability. The model demonstrates that personal innovativeness and perceived reachability have significant effects on the TAM framework.

Research limitations/implications - The relatively small sample size limits the generalization of the results.

Practical implications - Sales managers' intention to adopt mobile CRM can be explained by the extended TAM framework. Understanding the key factors that influence intention to adopt a mobile CRM system will aid companies in implementing it among their sales force. Companies willing to foster adoption of a mobile CRM system among the sales force could focus on communicating the usefulness of using the system and benefits gained from 
enhanced reachability. Recruiting sales people with strong personal innovativeness is beneficial.

Originality/value - This study responds the calls for studies on mobile platforms and on the use of mobile B2B applications in sales force management. It is among the first attempts to incorporate variables derived from mobile technology acceptance literature among the sales force into the TAM framework, to better explain acceptance of mobile CRM systems.

Keywords: Technology acceptance, Personal innovativeness, perceived reachability in the domain of IT, perceived risk, CRM system, mobile technology 


\section{INTRODUCTION}

The Marketing Science Institute (MSI) identifies mobile platforms and their impact on the operation of markets as a key research priority (MSI, 2012). Specifically, the MSI calls for research on the use of business-to-business (B2B) applications in sales force management. Previous research suggests that adoption of sales force automation (SFA) systems is a twostage process that starts with an organization deciding to adopt a SFA system, and ends with the decision of the individual salesperson to adopt the technology or not (Basole et al., 2013). Most research on the adoption of SFA from a salesperson's perspective has started from the perspective of technology adoption theories such as TAM (technology acceptance model) and its modifications (Buttle et al., 2006). However, research dealing with mobile SFA system adoption is in its infancy. From the sales force management perspective, the terms 'mobile SFA' and 'mobile CRM' both refer to a means of providing the members of the sales force with access to enterprise data such as customer and product information, orders and sales pipeline information irrespective of their location. Such salespeople should also be able to use a mobile device such as a smartphone or a tablet to access their company's CRM system and update information. The interest in this paper is in examining a salesperson's intention to access and update a CRM system via a mobile application.

Although adoption of SFA systems has been examined over the past thirty years (Buttle et al., 2006), and there are many examples of studies examining the adoption of mobile technology and mobile services (Balocco et al., 2009; Kim and Garrison, 2009, Liang et al., 2007), to the best of the authors' knowledge, this is the first study to combine these two perspectives in an attempt to understand how sales forces adopt mobile technology for the purposes of accessing CRM systems. Specifically, the objective of the study is to extend the TAM framework into the mobile CRM system adoption context. Drawing on theories of mobile technology and SFA system adoption, we postulate that personal innovativeness, 
perceived risk, and perceived reachability are the key additional variables affecting sales managers' intention to adopt a mobile CRM system. Theoretically we explore how these three constructs extend the TAM framework.

Below we present the theoretical framework and the related hypotheses before detailing the research methodology. The third section covers the analysis and results of the research. This is followed by a discussion of the study outcomes and their implications for academics and practitioners, the limitations of the study, directions for future research, and a conclusion.

\section{THEORETICAL BACKGROUND AND HYPOTHESES DEVELOPMENT}

Traditionally, the adoption of mobile technology has been investigated through the TAM (Davis, 1989; Davis et al., 1989) and its modifications such as TAM2 (Venkatesh and Davis, 2000) and the Unified Theory of Acceptance and Use of Technology (UTAUT) (Venkatesh et al., 2003). Similar theoretical foundations have been used to explain the acceptance of SFA (Buttle et al., 2006; Schillewaert et al., 2005). This stream of literature suggests that a salesperson's adoption of SFA is a function of usefulness and ease of use, which together influence the attitude to using the system, which in turn affects the intention to use it (Avlonitis and Panagopoulos, 2005). Additionally, research has identified various other antecedents to intention, such as intrapersonal attributes like innovativeness; facilitating conditions (such as availability of training and technical support); and the expectations of salespeople relating to the implementation of the technology (Buttle et al., 2006).

Drawing on previous studies of SFA system adoption (Avlonitis and Panagopoulos, 2005; Schillewaert et al., 2005) and mobile technology adoption (Kim et al., 2007; Lee and Park, 2008; Liang et al., 2007), we propose a conceptual model to examine a salesperson's intention to use mobile CRM (see Figure 1). This framework proposes that intention to use mobile CRM is directly affected by attitude and perceived reachability (PR), directly and indirectly by perceived risk (RISK) and perceived usefulness (PU), and indirectly by personal 
innovativeness in the domain of IT (PIIT) and perceived ease of use (PEOU). In the next section we discuss the extended TAM framework in the light of the drivers of mobile technology adoption, namely, PIIT, RISK, and PR.

"Take in Figure 1 about here"

\subsection{Personal innovativeness}

The subject of this study is the adoption of mobile CRM systems by salespeople and it is therefore necessary to examine the nature of mobile sales work and how a salesperson's innovativeness affects adoption. Moreover, PIIT has been identified as an important construct in SFA adoption (Kumar and Reinartz, 2012; Schillewaert et al., 2005). PIIT refers to an individual's willingness to try out new information technology (Agarwal and Prasad, 1998). In the sales force context, Schillewaert et al. (2005, p. 326) defined PIIT as "a predisposition or attitude describing a salesperson's learned and enduring cognitive evaluations, emotional feelings, and action tendencies toward adopting new information technologies."

Previous research highlights two key relationships that mediate the influence of innovativeness on the adoption process. The relationship between PIIT and PEOU and PIIT and PU are widely recognized (Sultan and Chan, 2000; Thakur and Srivastava, 2014). Innovative people, in general, have more experience of using information systems, which can have a positive effect on PEOU (Avlonitis and Panagopoulos, 2005). Thus, even without system-specific experience, innovative individuals are expected to be more likely to form favorable perceptions of the usability of a system. As individuals gain experience with a specific system, their perceptions of that system can be expected to alter (Venkatesh et al., 2003). This implies that the importance of PIIT for PEOU will be particularly apparent in the earlier stages of adoption. Moreover, the relationship can be expected to be more prominent in the context of this study, as the idea of using CRM systems on a mobile device is relatively 
new. Various studies of mobile technology offer an empirical validation of the relationship between PIIT and PEOU (Lu et al., 2008; Zarmpou et al., 2012), and such studies offer

grounds for proposing H1 (Table 1). Second, from a more generic perspective, Schillewaert et al. (2005) postulate that innovative salespeople are more familiar with using computer technology, more adept at using it, and more able to see a system's usefulness in relation to their sales activities. Similar conclusions were drawn by Avlonitis and Panagopoulos (2005), and empirically validated for example by Lu et al. (2005). Accordingly, we wish to reconfirm this view $(\mathrm{H} 2)$.

"Take in Table 1 about here"

\subsection{Perceived risk}

Perceived risk is regarded as a negative consequence that arises from the purchase of a new product (Dholakia, 2001). Several dimensions of risk have been identified, and they vary across products and services (Kaplan et al., 1974). For example, research on mobile payment adoption identifies three risk dimensions - security, privacy, and monetary risk (Thakur and Srivastava, 2014). Security risk relates to the technical aspects of the system (Flavián and Guinalíu, 2006) whereas privacy risk refers to the inappropriate use of personal information or invasion of privacy (Nyshadham, 2000). In the context of our study, security and privacy risks are likely to be present as: 1) the field sales force's mobile devices contain company sensitive data and devices are susceptible to loss and theft, 2) data transmitted over networks may be intercepted by third parties.

The perceived risks of mobile CRM may also be based on the fact that it uses emergent technology which users may have little experience of (Luo et al., 2010). In the technology acceptance context, perceived risk has been found to be negatively associated with attitude (Ku et al., 2009; Akturan and Tezcan, 2012) and intention to adopt mobile technology (Thakur and Srivastava, 2014). However, its effect on acceptance is not clear (DelVecchio 
and Smith, 2005). Based on past research and the context of this study we present H3 and H4 (see Table 1).

\subsection{Perceived reachability}

Perceived reachability (PR) is a relatively new concept in IS/IT research, but has been used with research dealing with wireless technology for example by Kim and Garrison (2009), who were among the first to incorporate PR into the TAM framework. PR refers to "an individual's perception regarding the degree to which he or she can 'reach' other individuals 'anytime-and-anywhere" via mobile wireless technology" (Kim and Garrison, 2009, p. 326). Thus, PR refers to the capability to connect with others. Sales jobs can necessitate spending a considerable amount of work time away from the employer's base, and it can be argued that mobile technology provides an ideal enhancement for salespeople. Indeed real time responses to customers improve the working processes of salespeople (Sheng et al. 2005). Moreover, Rivers and Dart (1999) suggested that timely information could improve the quality of any sales effort. PR thus provides sales people freedom in time and location that influence the acceptance of mobile CRM. Given these considerations, and the positive relationship between PR and BI (Kim and Garrison, 2009), PR emphasizes the potential value of mobile technology available to salespeople. These findings suggest that PR and BI are positively linked (H5).

\subsection{Age and CRM experience}

We include two covariates, age and CRM experience in our model. Age has previously been used to predict user acceptance of information technology (Nysveen et al., 2005; Venkatesh et al., 2003). This stream of research proposes that younger people are more eager to adopt information technology. Experience of using technology has a significant impact on an individual's attitude and intention to use technology (Igbaria and Guimaraes, 1995; Kim 
and Garrison, 2009). We propose that that the more experienced users are, the more likely they are to adopt information technology.

\section{METHODOLOGY}

We collected data through an online survey targeted at sales managers of five B2B firms in Finland: four were industrial firms representing the pulp and paper industry, power solutions and renewable energy, and one was an education services firm. The firms represented industries where the primary means of communicating with customers was through salespeople. Moreover these five firms met consumer needs with a wide variety of products and were also partners in a two-year university research project dealing with B2B digital marketing, and were planning to implement mobile SFA technology. In summer 2012, sales managers in the participating firms were sent an email explaining the purpose of the research with a link to the online survey. The email generated 105 responses: a response rate of approximately $50 \%$. Comparisons of early $(\mathrm{N}=25)$ and late $(\mathrm{N}=25)$ respondents revealed no significant differences in the item means, signifying the absence of nonresponse bias. The sample respondents were predominantly male $(88 \%)$, and their ages ranged from 24 to 65 (with a mean age of 45). The respondents had been with their firm for an average of 14 years and were working in 33 different countries. Slightly over half $(52 \%)$ of the respondents represented the pulp and paper industry, around one-third (33\%) were from the power solutions firm, $10 \%$ from the renewable energy firm and $5 \%$ from the education services business.

\subsection{Measures}

The survey was conducted in English, and the definitions of the specific terms (mobile device, CRM system, and mobile CRM) were provided to the respondents at the outset. Mobile device in this survey referred to a small portable communication device, including a 
mobile phone, a smartphone such as an iPhone, a tablet (such as an iPad), or a small laptop equipped with $\mathrm{Wi}-\mathrm{Fi}$ and $3 \mathrm{G}$ or $4 \mathrm{G}$ and GPS. CRM system was defined as specific collaborative software used to organize, automate, and synchronize business processes such as sales activities, marketing, customer service, and technical support. Mobile CRM was defined as a means of accessing the company's CRM system via a mobile application.

All the constructs (see Appendix) were measured with established and validated scales. PIIT and PU were measured with the items used by Lu et al. (2005). Items measuring PEOU, PR and BI were adopted from Kim and Garrison's work (2009). The perceived risk scale consisted of three items adopted from Dholakia (2001). The informants' attitude toward adopting mobile CRM in the course of their work within the next 12 months was measured with five items originally devised by Ajzen (2002) and Venkatesh et al. (2003). A person's intention to use mobile CRM was assessed through the additional question "If your organization allowed and/or supported mobile CRM...” and a choice of responses starting with "I would.../predict.../plan..."

We include two control variables: Respondent's age was measured on a five-point scale, while experience of CRM software was measured on a single item scale anchored with 1 (not in use) and 4 (in daily use).

\section{RESULTS}

The respondents were experienced users of mobile technology as $85 \%$ of the respondents used smartphones in their free time, and slightly over half (53\%) used tablets on a daily basis. Thus, the respondents had sufficient experience of mobile devices and services to provide reliable answers to the survey. It appears that a laptop is currently the mobile device most often used to access a company's CRM system (87\% usage). Only 7\% had used smartphones and $4 \%$ tablets for accessing the CRM system. In response to the question 
“what mobile device would you like to use to access the CRM?" on a scale ranging from 1 (not at all willing) to 7 (extremely willing), the responses suggested that a tablet PC (mean = 5.82) was the most preferred, followed by a laptop (mean $=5.65)$ and then a smartphone (mean $=4.86)$. In total $78 \%$ were willing or extremely willing to use tablet PCs, $70 \%$ willing or extremely willing to use laptops and $50 \%$ willing or extremely willing to use smartphones to access their company's CRM system. In addition, close to three out of four (74 \%) were at least somewhat likely to use their company's CRM system more actively if they had more developed mobile devices to use.

With respect to our control variable experience of CRM software, over half (60\%) used CRM on a daily basis, $19 \%$ weekly, $9 \%$ monthly, and $13 \%$ of the respondents had no experience of using CRM software.

\subsection{Confirmatory phase}

Given that our conceptual model comprises a large number of indicators and constructs and the sample size is relatively small, the use of the PLS-SEM approach is appropriate (Hair et al., 2013). Data were analyzed using the SmartPLS software (Ringle et al., 2005). All items indicated high levels of internal consistency, as Composite Reliabilities for the constructs were equal or larger than 0.84 (see Table 2), and Cronbach's alphas ranged from 0.76 to 0.97 . The factor loadings were high ( $\geq .59$ ), Average Variance Extracted (AVE) values were above 0.50 and the square root of AVE was larger than the correlation between the latent variable and all other latent constructs, thus confirming the convergent and discriminant validity of the model (Table 2).

"Take in Table 2 about here"

As in any other survey study, common method bias is always present to some extent (Podsakoff et al., 2003), and we took several measures to mitigate its effect. First, we hid the 
respondents' identities and varied the order of items in the questionnaire. We then undertook a series of measures to evaluate to what extent common method bias was present. First, we ran the Harman's (1967) one factor test. This revealed that the measurement model factors were present and that the greatest variance explained by one factor was just $18.9 \%$, indicating that common method bias was unlikely to contaminate our results. Second, following Podsakoff et al. (2003), we ran a PLS model with a common method factor with indicators of all the principal constructs. Each indicator's variances proved to be substantively explained by the principal construct. We found that the average variance substantively explained the variance of the indicators $(0.753)$; while the average method based variance was 0.013 . We also observed that most method factor coefficients were not significant. Given the magnitude and the insignificance of method variance, common method bias is unlikely to be a serious concern in this study.

We utilized a path-weighting scheme to estimate paths between the latent variables. To determine the significance of each estimated path, we applied a standard bootstrapping procedure with 5,000 re-samples consisting of the same number of cases as in the original sample (Hair et al., 2013). The results of the analysis are displayed in Table 3.

"Take in Table 3 about here"

Overall, the high $R^{2}$ and $Q^{2}$ (predictive relevance) values of the model constructs provide support for the model's predictive relevance.

\subsection{Hypotheses testing}

We find that PI is positively related to PEOU (H1), whereas its direct effect on PU is not significant (H2). These findings indicate that the effect of PI on PU might be indirect and fully mediated by PEOU. This mediation was confirmed as the indirect effect was strong (0.373) and significant $(p<0.01)$ and the Variance Accounted For (VAF) value of 0.697 indicates strong partial mediation (Hair et al., 2013). In line with the extant literature (Lu et 
al., 2005; Lu et al., 2008; Zarmpou et al., 2012), we confirm the negative effect of perceived risk on attitude (H2), but not the notion that perceived risk is negatively related to BI (H3). Finally, in line with theory, the positive effect of PR on BI (H5) was confirmed by the data. The path coefficient of $0.303(p<0.01)$ and the $f^{2}$ effect size $(0.190)$ indicates that the effect is of medium strength. In line with the literature, we can further confirm that PEOU is positively related to PU (Lee and Park, 2008), PU is positively related to attitude and intention (Kim and Garrison, 2009), and that attitude is positively related to intention (Zhang et al., 2012). However, the positive relationship between PEOU and attitude was not confirmed. This can be explained by the mobile context, because PEOU becomes less important over time when users already have experience of mobile technology (cf. Venkatesh et al., 2003). In terms of control variables, we found that neither age nor CRM experience have a significant influence on attitude or intention.

Following Hair et al. (2013), although not formally hypothesized, we investigated the total effects of the path model and calculated the indirect and mediation effects. As Table 4 shows, PU has the largest total effect on intention $(0.565, p<0.01)$, followed by the effect of PIIT $(0.296, p<0.01)$ and PEOU $(0.273, p<0.01)$. The significant role of PIIT in determining an individual's acceptance of mobile CRM is further evidenced by its strong total effect on attitude $(0.356, p<0.01)$. The total effect of PEOU on attitude is also significant $(0.323, p<0.01)$, indicating that its effect is fully mediated ${ }^{1}$ by PU (given the lack of a significant direct effect between PEOU and attitude in the presence of the mediator PU).

"Take in Table 4 about here"

\section{DISCUSSION}

In response to the calls for research on mobile technology in B2B settings (MSI, 2012), we examined sales managers' intention to adopt mobile CRM systems in the course of their

\footnotetext{
${ }^{1}$ Indirect effect $(0.350)$ is significant $(p<0.01)$
} 
work and incorporated personal innovativeness in the domain of IT, perceived risk and perceived reachability within an extended TAM. We find that perceived innovativeness, perceived risk, and perceived reachability, alongside the well-known TAM constructs, are important drivers of mobile CRM system adoption among B2B sales managers. The majority of our findings are in line with prior studies such as those dealing with the adoption of mobile technology (Kim and Garrison, 2009; Lee and Park, 2008), with two notable exceptions. First, we did not find support for the relationships between PI and PU and between perceived risk and intention. A possible explanation could be that PI was found to affect PU only through PEOU. Second, the lack of a link between perceived risk and intention can be explained by the fact that adoption of new technology is affected more by other factors (see DelVecchio and Smith, 2005; Hirunyawipada and Paswan, 2006). In addition, as our respondents did not perceive much risk related to mobile devices and applications, the perception of risk may not have much to do with intention.

Our study makes an important theoretical contribution to the research on technology acceptance (Davis, 1989; Davis et al., 1989) in general and to mobile technology acceptance literature in particular (Kim et al., 2007; Kim and Garrison, 2009; Lee and Park, 2008; Liang et al., 2007). Specifically we demonstrate that extending the TAM framework with perceived innovativeness, perceived risk, and perceived reachability, could better explain adoption behaviors.

Interpreting our results gives rise to three specific managerial implications. First, this study can aid B2B companies and developers of mobile CRM systems in understanding the key factors that can play a role in influencing intention to adopt a mobile CRM system from a sales manager's perspective. For example, PU of the system is the key variable influencing intention, and sales managers generally consider mobile CRM systems useful, as manifested by the relatively high mean scores of the items (Table 2). As this clearly encourages 
acceptance, the usefulness of the mobile CRM system should be constantly communicated to sales managers. Second, this research shows that personal innovativeness in the domain of IT is a strong predictor of intervening variables influencing intention in the mobile CRM system context. Thus, the more innovative the salespeople, the more likely they are to adopt a mobile CRM system. Managers should therefore pay more attention to the personal innovativeness of salespeople (and perhaps place less emphasis on a person's age or experience of using a system) in the recruiting process. Third, we show that perceived risk only influences attitude and not intention. Input from our sample who had significant experience of using smartphones and tablets indicates that companies do not need to educate their sales force on the security and privacy risks related to mobile CRM. However, this seems only to be the case when users have prior experience of using the devices or system. Prior research has shown that the adoption of technological innovations typically involves risks, but they appear to diminish when users become accustomed to the system.

As with any study, there are certain limitations that should be taken into account when interpreting the results. The central limitation of the study arises from the relatively small sample size $(\mathrm{N}=105)$, and the high proportion of male respondents. Therefore caution must be exercised in generalizing the results. Future studies should therefore be conducted with larger samples to test the model. Second, although we attempted to reduce common method variance, and found that it did not threaten the findings of the study, only the adoption of a longitudinal study design could completely rule out its having some effect. Against this backdrop, we encourage other researchers to develop and test our model to further elucidate the factors that affect salespeople's intentions to use mobile CRM in the course of their work.

\section{CONCLUSIONS}

The objective of the study was to extend and contextualize the TAM framework into the mobile CRM adoption context. We extended TAM by incorporating three key constructs: 
personal innovativeness in the domain of IT, perceived risk and perceived reachability. We tested our model on a sample of 105 sales managers from five B2B firms. The results demonstrated that our extended model was better able to explain adoption behaviors, thus providing support for the extended TAM model in the mobile context. Specifically, we find that PIIT and PR have significant effects on the TAM framework. Overall, the findings extend our understanding of the adoption of mobile CRM systems among B2B sales managers and provide practical insights into the behaviors of salespeople.

\section{References}

Agarwal, R. and Prasad, J. (1998), "A conceptual and operational definition of personal innovativeness in the domain of information technology", Information Systems Research, Vol. 9 No. 2, pp. 204-215.

Akturan, U. and Tezcan, N. (2012), "Mobile banking adoption of the youth market: Perceptions and intentions", Marketing Intelligence \& Planning, Vol. 30 No. 4, pp. 444-459.

Ajzen, I. (1991), "The theory of planned behavior", Organizational Behavior and Human Decision Processes, Vol. 50 No. 2, pp. 179-211.

Ajzen, I. (2002), "Constructing a TpB questionnaire: Conceptual and methodological considerations", Retrieved September 13, 2012, from: http://wwwunix.oit.umass.edu/ aizen/pdf/tpb.measurement.pdf

Avlonitis, G.J. and Panagopoulos, N.G. (2005), "Antecedents and consequences of CRM technology acceptance in the sales force", Industrial Marketing Management, Vol. 34 No. 4, pp. 355-368.

Balocco, R., Mogre, R. and Toletti, G (2009), "Mobile internet and SMEs: a focus on the adoption", Industrial Management \& Data Systems, Vol. 109 No. 2, pp. 245-261.

Basole, R.C., Seuss, C.D. and Rouse, W.B. (2013), "IT innovation adoption by enterprises: Knowledge discovery through text analytics", Decision Support Systems, Vol. 54, pp. 1044-1054.

Buttle, F., Ang, L. and Iriana, R. (2006), "Sales force automation: review, critique, research agenda", International Journal of Management Reviews, Vol. 8 No. 4, pp. 213-231.

Davis, F.D. (1989), "Perceived usefulness, perceived ease of use, and user acceptance of information technology", MIS Quarterly, Vol. 13 No. 3, pp. 319-340. 
Davis, F.D., Bagozzi, R.P. and Warshaw P.R. (1989), "User acceptance of computer technology: A comparison of two theoretical models", Management Science, Vol. 35 No. 8, pp. 982-1003.

DelVecchio, D. and Smith, D.C. (2005), "Brand-extension price premiums: the effects of perceived fit and extension product category risk", Journal of the Academy of Marketing Science, Vol. 33 No.2, pp. 184-196.

Dholakia, U.M. (2001), "A motivational process model of product involvement and consumer risk perception”, European Journal of Marketing, Vol. 35, pp. 1340-1360.

Flavián, C. and Guinalíu M. (2006), "Consumer trust, perceived security and privacy policy: Three basic elements of loyalty to a web site", Industrial Management \& Data Systems, Vol. 106 No. 5, pp. 601-620.

Hair, J.F. Jr., Hult, G.T.M., Ringle, C.M. and Sarstedt, M. (2013), A Primer on Partial Least Squares Structural Equation Modeling (PLS-SEM), Sage, Los Angeles.

Hirunyawipada, T. and Paswan, A.K. (2006), "Consumer innovativeness and perceived risk: implications for high technology product adoption", Journal of Consumer Marketing, Vol. 23 No. 4, pp. 182-198.

Harman, H.H. (1967), Modern Factor Analysis, University of Chicago Press, Chicago.

Igbaria, M. and Guimaraes, T. (1995), "Testing the determinants of micro-computer usage via a structural equation model", Journal of MIS Research, Vol. 11 No. 4, pp. 87-114.

Kaplan, L.B., Szybillo, G.J. and Jacoby, J. (1974), "Components of perceived risk in product purchase: A cross-validation”, Journal of Applied Psychology, Vol. 59 No. 3, pp. 287-291.

Kim, H.-W., Chan, H.-C. and Gupta, S. (2007), "Value-based adoption of mobile Internet: An empirical investigation”, Decision Support Systems, Vol. 43 No. 1, pp. 111-126.

Kim, S. and Garrison, G. (2009), "Investigating mobile wireless technology adoption: An extension of the technology acceptance model", Information Systems Frontiers, Vol. 11 No. 3, pp. 323-333.

Ku, C., Lai, L., Chang, Y. and Lai, C. (2009), "User acceptance of the mobile solution office by using 3G technology: A study of the high-tech and manufacturing industries in Taiwan", Proceedings of the Eighth International Conference on Mobile Business (pp. 149-153), Los Alamitos, CA: IEEE Computer Society.

Kumar, V. and Reinartz, W. (2012), "Customer relationship management issues in the business-to-business context", in Kumar, V. and Reinartz, W. (Eds.), Customer Relationship Management: Concept, Strategy and Tools, Springer Berlin Heidelberg, pp. 261-277.

Lee, T.M. and Park, C. (2008), "Mobile technology usage and B2B market performance under mandatory adoption", Industrial Marketing Management, Vol. 37 No. 7, pp. 833-840. 
Liang, T.-P., Huang, C.-W., Yeh, Y.-H. and Lin, B. (2007), “Adoption of mobile technology in business: a fit-viability model", Industrial Management \& Data Systems, Vol. 107 No. 8, pp. 1154-1169.

Lu, J., Liu, C., Yu, C.-S. and Wang, K. (2008), "Determinants of accepting wireless mobile data services in China", Information \& Management, Vol. 45 No. 1, pp. 52-64.

Lu, J. Yao, J.E. and Yu, C.-S. (2005), "Personal innovativeness, social influences and adoption of wireless Internet services via mobile technology", The Journal of Strategic Information Systems, Vol. 14 No. 3, pp. 245-268.

Luo, X., Li, H., Zhang, J. and Shim, J.P. (2010), "Examining multi-dimensional and multifaceted risk in initial acceptance of emerging technologies: An empirical study of mobile banking services", Decision Support Systems, Vol. 49 No. 2, pp. 222-234.

Marketing Science Institute (2012), “2012-2014 Research Priorities”, Retrieved November 18, 2012, from: http://www.msi.org/research/msi-research-priorities/

Nyshadham, E.A. (2000), "Privacypolicies of airtravelweb sites: asurvey and analysis", Journal of Air Transport Management, Vol. 6 No. 3, pp. 143-152.

Nysveen, H., Pedersen, P.E. and Thorbjørnsen, H. (2005), "Intentions to use mobile services: Antecedents and cross-service comparisons", Journal of the Academy of Marketing Science, Vol. 33 No. 3, pp. 330-346.

Parveen, F. and Sulaiman, A. (2008), "Technology complexity, personal innovativeness and intention to use wireless internet using mobile devices in Malaysia", International Review of Business Research Papers, Vol. 4 No. 5, pp. 1-10.

Podsakoff, P.M., MacKenzie, S.B., Lee, J.Y. and Podsakoff, N.P. (2003), "Common method biases in behavioral research: a critical review of the literature and recommended remedies", Journal of Applied Psychology, Vol. 88 No. 5, pp. 879-903.

Ringle, C., Wende, S. and Will, A. (2005), "SmartPLS: release 2.0 (beta)", Retrieved June 3, 2012, from: http://www.smartpls.de.

Rivers, M.L. and Dart, J. (1999), "The acquisition and use of sales force automation by midsized manufacturers", Journal of Personal Selling \& Sales Management, Vol. 19 No. 2, pp. 59-73.

Schillewaert, N., Ahearne, M.J., Frambach, R.T. and Moenaert, R.K. (2005), "The adoption of information technology in the sales force", Industrial Marketing Management, Vol. 34 No. 4, pp. 323-336.

Sheng, h., Nah, F.F. and Siau, K. (2005), "Strategic implications of mobile technology: A case study using value-focused thinking", Journal of Strategic Information Systems, Vol. 14 No. 3, pp. 269-290. 
Sultan, F. and Chan, L. (2000), "The adoption of new technology: the case of object-oriented computing in software companies", IEEE Transactions on Engineering Management, Vol. 47 No. 1, pp. 106-126.

Thakur, R. and Srivastava, M. (2014), “Adoption readiness, personal innovativeness, perceived risk and usage intention across customer groups for mobile payment services in India", Internet Research, Vol. 24 No. 3, pp. 369-392.

Venkatesh, V. and Davis, F.D. (2000), "A theoretical extension of the technology acceptance model: four longitudinal field studies", Management Science, Vol. 46 No. 2, pp. 186204.

Venkatesh, V., Morris, M.G., Davis, G.B. and Davis, F.D. (2003), "User acceptance of information technology: Toward a unified view", MIS Quarterly, Vol. 27 No. 3, pp. 425-478.

Yang, S., Lu, Y., Gupta, S., Cao, Y. and Zhang, R. (2012), "Mobile payment services adoption across time: An empirical study of the effects of behavioral beliefs, social influences, and personal traits", Computers in Human Behavior, Vol. 28 No. 1, pp. 129-142.

Zarmpou, T., Saprikis, V., Markos, A. and Vlachopoulou, M. (2012), 'Modeling users' acceptance of mobile services", Journal Electronic Commerce Research, Vol. 12 No. 2 , pp. $225-248$.

Zhang, L., Zhu, J. and Liu, Q. (2012), “A meta-analysis of mobile commerce adoption and the moderating effect of culture", Computers in Human Behavior, Vol. 28 No. 5, pp. 1902-1911. 


\section{FIGURES}

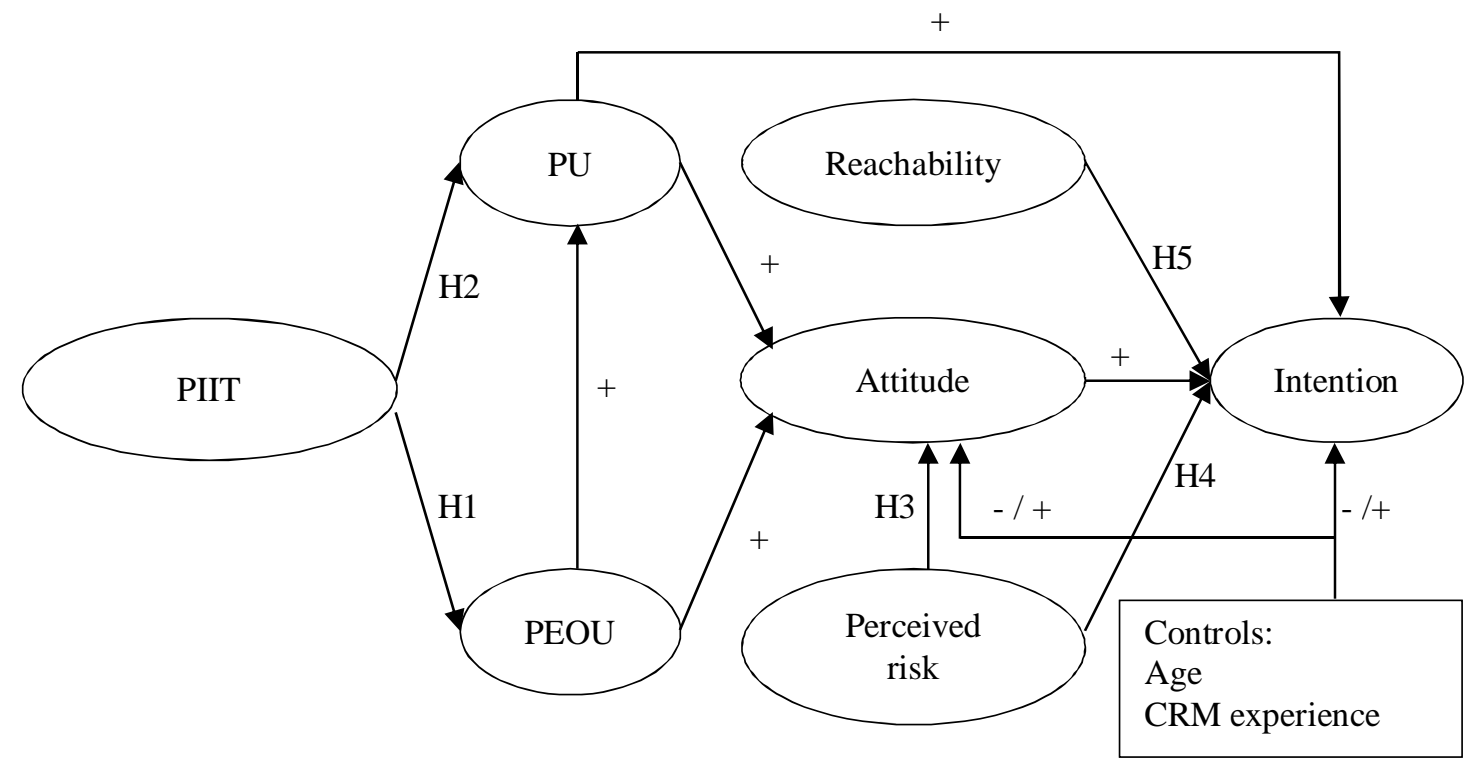

Figure 1. Conceptual model and hypotheses 


\section{TABLES}

Table 1: Summary of the conceptual model, hypotheses and supporting literature

\begin{tabular}{ll}
\hline Hypotheses & Key supporting literature \\
\hline H1 & $\begin{array}{l}\text { Lu } \text { et al. (2008); Lu } \text { et al. (2005); } \\
\text { Parveen and Sulaiman (2008); Zarmpou } \\
\text { et al. (2012) }\end{array}$ \\
H2 & $\begin{array}{l}\text { Avlonitis and Panagopoulos (2005); Lu } \\
\text { et al. (2005); Schillewaert } \text { et al. (2005); } \\
\text { PIIT is positively related to PU }\end{array}$ \\
& $\begin{array}{l}\text { Yang } \text { et al. (2012); Zarmpou } \text { et al. } \\
(2012)\end{array}$ \\
H3 & Akturan and Tezcan (2012); Ku et al.. \\
Perceived risk is negatively related to attitude & (2009) \\
H4 & Luo et al. (2010); Thakur and Srivastava \\
Perceived risk is negatively related to intention & (2014); Yang et al. (2012) \\
H5 & Kim and Garrison (2009); Rivers and \\
Perceived reachability is positively related to intention & Dart (1999); Sheng et al. (2005) \\
\hline
\end{tabular}


Table 2. AVE, reliability, construct correlations, square root of AVE (on the diagonal), means and standard deviations

\begin{tabular}{|c|c|c|c|c|c|c|c|c|c|c|c|}
\hline & AVE & $\mathrm{CR}^{1}$ & PIIT & PEOU & PU & RISK & PR & ATT & $\mathrm{BI}$ & Age & EXP \\
\hline $\begin{array}{l}\text { Personal innovativeness } \\
\text { (PIIT) }\end{array}$ & 0.771 & 0.910 & 0.878 & & & & & & & & \\
\hline $\begin{array}{l}\text { Perceived ease of use } \\
\text { (PEOU) }\end{array}$ & 0.577 & 0.891 & 0.750 & 0.760 & & & & & & & \\
\hline Perceived usefulness (PU) & 0.873 & 0.976 & 0.535 & 0.619 & 0.934 & & & & & & \\
\hline Perceived risk (RISK) & 0.650 & 0.844 & $0 . \overline{279}$ & -0.213 & $0 . \overline{201}$ & 0.806 & & & & & \\
\hline Perceived reachability (PR) & 0.680 & 0.864 & 0.287 & 0.443 & 0.408 & 0.174 & 0.825 & & & & \\
\hline Attitude (ATT) & 0.856 & 0.968 & 0.467 & 0.482 & 0.749 & $0 . \overline{379}$ & 0.349 & 0.925 & & & \\
\hline Behavioral intention (BI) & 0.784 & 0.916 & 0.447 & 0.477 & 0.698 & 0.139 & 0.546 & 0.653 & 0.885 & & \\
\hline Age (Age) & $\mathrm{n} / \mathrm{a}^{2}$ & $\mathrm{n} / \mathrm{a}$ & $0 . \overline{139}$ & -0.172 & 0.057 & 0.082 & 0.024 & 0.054 & $\begin{array}{c}- \\
0.015\end{array}$ & $\mathrm{n} / \mathrm{a}$ & \\
\hline CRM Experience (EXP) & $\mathrm{n} / \mathrm{a}$ & $\mathrm{n} / \mathrm{a}$ & 0.233 & 0.138 & 0.260 & $\begin{array}{c}- \\
0.019\end{array}$ & 0.190 & 0.260 & 0.298 & $\begin{array}{c}- \\
0.036\end{array}$ & $\mathrm{n} / \mathrm{a}$ \\
\hline Mean & & & 4.82 & 5.41 & 4.87 & 3.76 & 5.72 & 5.09 & 4.98 & $\mathrm{n} / \mathrm{a}$ & $\mathrm{n} / \mathrm{a}$ \\
\hline Standard deviation & & & 1.48 & 1.24 & 1.70 & 1.67 & 1.30 & 1.51 & 1.87 & $\mathrm{n} / \mathrm{a}$ & $\mathrm{n} / \mathrm{a}$ \\
\hline
\end{tabular}


Table 3. Structural model results

\begin{tabular}{|c|c|c|c|c|c|}
\hline & $\beta^{\mathrm{a}}$ & $f^{2 \mathrm{~b}}$ & $R^{2 \mathrm{c}}$ & $Q^{2 \mathrm{~d}}$ & $q^{2 \mathrm{e}}$ \\
\hline H1: PIIT $\rightarrow$ PEOU & $0.750 * *$ & $\mathrm{n} / \mathrm{a}^{\mathrm{g}}$ & 0.563 & 0.318 & $\mathrm{n} / \mathrm{a}$ \\
\hline $\mathrm{H} 2: \mathrm{PIIT} \rightarrow \mathrm{PU}$ & $0.162 \mathrm{~ns}^{\mathrm{f}}$ & $\mathrm{n} / \mathrm{a}$ & \multirow{2}{*}{0.394} & \multirow{2}{*}{0.300} & $\mathrm{n} / \mathrm{a}$ \\
\hline $\mathrm{PEOU} \rightarrow \mathrm{PU}$ & $0.497 * *$ & 0.178 & & & 0.120 \\
\hline H3: Perceived risk $\rightarrow$ attitude & $-0.236 * *$ & 0.139 & \multirow{5}{*}{0.627} & \multirow{5}{*}{0.471} & 0.066 \\
\hline $\mathrm{PEOU} \rightarrow$ attitude & $-0.027 \mathrm{~ns}$ & 0.000 & & & -0.013 \\
\hline $\mathrm{PU} \rightarrow$ attitude & $0.704 * *$ & 0.737 & & & 0.471 \\
\hline Age $\rightarrow$ attitude & $-0.076 \mathrm{~ns}$ & 0.013 & & & -0.041 \\
\hline CRM experience $\rightarrow$ attitude & $0.073 \mathrm{~ns}$ & 0.013 & & & 0.001 \\
\hline H4: Perceived risk $\rightarrow$ intention & $0.103 \mathrm{~ns}$ & 0.023 & \multirow{6}{*}{0.616} & \multirow{6}{*}{0.402} & 0.010 \\
\hline H5: Perceived reachability $\rightarrow$ intention & $0.303 * *$ & 0.190 & & & 0.062 \\
\hline $\mathrm{PU} \rightarrow$ intention & $0.353 * *$ & 0.128 & & & 0.028 \\
\hline Attitude $\rightarrow$ intention & $0.301 * *$ & 0.086 & & & 0.024 \\
\hline Age $\rightarrow$ intention & $-0.032 \mathrm{~ns}$ & 0.003 & & & -0.001 \\
\hline CRM experience $\rightarrow$ intention & $0.072 \mathrm{~ns}$ & 0.010 & & & 0.000 \\
\hline
\end{tabular}

(two-sided test)

${ }^{\text {a }} \beta-$ Path coefficient

${ }^{\mathrm{b}} f^{2}$ - Effect size indicates the relative impact a construct has in producing the $R^{2}$ value of the endogenous construct. $f^{2}$ smaller than 0.02 indicates a small effect, values between $0.02-0.15$ indicate a medium effect and values larger than 0.35 indicate large effects of the exogenous latent variable.

c $R^{2}$ - Coefficient of determination indicates the proportion of an endogenous construct's variance that is explained by its predictor constructs.

${ }^{\mathrm{d}} Q^{2}-$ Predictive relevance. Values larger than zero indicate the path model's predictive relevance for the particular construct.

${ }_{\mathrm{e}}^{\mathrm{e}} q^{2}-$ Effect size indicates the relative predictive relevance of a predictor construct on an endogenous construct.

${ }^{\mathrm{f}} \mathrm{ns}$ - Not significant

${ }^{\mathrm{g}} \mathrm{n} / \mathrm{a}$ - Not applicable 
Table 4. Total effects

\begin{tabular}{lcc}
\hline & Total effects & S.E. \\
\hline PIIT $\rightarrow$ attitude & $0.356^{* *}$ & 0.072 \\
$\mathrm{PIIT} \rightarrow$ intention & $0.296^{* *}$ & 0.069 \\
$\mathrm{PEOU} \rightarrow$ attitude & $0.323^{* *}$ & 0.119 \\
$\mathrm{PEOU} \rightarrow$ intention & $0.273^{* *}$ & 0.104 \\
$\mathrm{PU} \rightarrow$ intention & $0.565^{* *}$ & 0.107 \\
Perceived risk $\rightarrow$ intention & $0.032 \mathrm{~ns}$ & 0.076 \\
\hline$* * p<0.01$ (two-sided test); ns - not significant; S.E. - Standard Error &
\end{tabular}




\section{APPENDIX}

\section{SUPPLEMENTARY MATERIAL (ONLY AVAILABLE ONLINE)}

\section{APPENDIX}

\section{LIST OF ITEMS}

Personal innovativeness in the domain of IT (PIIT)

If I hear about a new mobile technology, I would look for ways of experimenting with it

\section{Perceived ease of use (PEOU)}

I would find it easy to access mobile services (such as mobile email) and/or applications (such as .83 iPhone/iPad apps) to do what I want it to do

I find tablets easy to use

My interaction with mobile applications is clear and understandable

I am usually quick to learn to use mobile devices

74

I find mobile applications to be flexible when interacting with them

It would be easy for me to become skilled at using mobile

.74

Salesforce.com on a mobile (or other CRM software)

Perceived usefulness (PU)

Use of mobile CRM could reduce the time needed for my work

Use of mobile CRM could significantly increase the quality of output of my work

Use of mobile CRM could increase the effectiveness of my work performance

Use of mobile CRM could increase the quality of output for the same amount of effort

.93

Considering everything, the use of mobile CRM could assist my work

Overall, I would find mobile CRM useful in my daily life

Perceived risk ("If using mobile devices and applications...")

I would worry about how reliable they would be

I would be afraid that they would not provide me with level of benefits that I expected

I would be concerned about security risks

Perceived reachability $(\mathbf{P R})$

In my job, anytime-and-anywhere connectivity is important

In my job, the technology to provide communication (email, instant messengers, video conferences, online phone calls) is important

In my job, all day network accessibility is important

\section{Attitude}

The use of mobile CRM is an extremely negative...extremely positive idea

The use of mobile CRM is an extremely bad...extremely good idea

The use of mobile CRM is an extremely harmful...extremely beneficial idea

I dislike... like the idea of using mobile CRM

The use of mobile CRM is worthless...valuable

Intention (If your organization allowed and/or supported mobile CRM...)

I would like to use mobile CRM in the next 12 months

I predict I would use mobile CRM on a smartphone

I predict I would use mobile CRM on a tablet PC

Note: If not described otherwise, all items were measured on 7-point scales anchored with 1(strongly disagree) and 7 (strongly agree). 
